\title{
Mediação da leitura na biblioteca escolar: práticas e fazeres na formação de leitores
}

Martha Suzana Cabral Nunes ${ }^{I}$

http://orcid.org/0000-0002-0587-5354

\section{Flaviana de Oliveira Santos ${ }^{I I}$}

${ }^{I}$ Universidade Federal de Sergipe, SE, Brasil.

Doutora em Ciência da Informação.

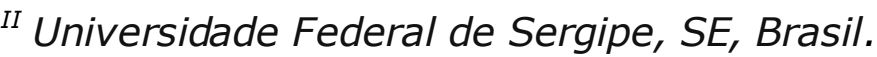

Bibliotecária.

http://dx.doi.org/10.1590/1981-5344/3725

Este artigo tem comoobjetivo geral discutir a biblioteca escolar como espaço privilegiado para amediação de leitura a partir da percepção dos alunos. Os objetivos específicos são: analisar as práticas de mediação na biblioteca escolar como potencializadoras da leitura; identificar a biblioteca escolar como espaço privilegiado para mediação da leitura; e discutir o papel do bibliotecário na promoção da aprendizagem e da leitura.A pesquisa foi exploratória e de abordagem qualitativa. Foi desenvolvida observação participante e análise da aprendizagem a partir de experiências de mediação da leitura na biblioteca da Escola SESC Unidade Siqueira Campos. Foi proposta uma adaptação do trabalho de Gardiès (2014), onde foram analisados os seguintes aspectos do processo de mediação, tais como o processo documentário, o processo informacional e o processo comunicacional. A biblioteca foi escolhida por critério de amostragem por acessibilidade, possuindo bibliotecário em seu quadro de funcionários que desenvolve ações de 
leitura com turmas de alunos. A pesquisa foi realizada com uma turma de trinta e seis alunos do $4^{\circ}$ ano do Ensino Fundamental. Considera-se que a mediação é um fator primordial para o incentivo e a construção do hábito da leitura, que deve ser responsabilidade não só da escola, mas também da família.

Palavras-chave: Biblioteca escolar; Bibliotecário; Leitor; Leitura ; Mediação.

\section{Mediation of reading in the school library: practice and do in the training of readers}

This article aims to discuss the school library as a privileged space for reading mediation from the students' perception. The specific objectives are: to analyze the mediation practices in the school library as reading enhancers; identify the school library as a privileged space for reading mediation; and discuss the role of the librarian in promoting learning and reading. The research was exploratory and qualitative approach. Participant observation and learning analysis were developed from reading mediation experiences in the SESC School Siqueira Campos Library. An adaptation of Gardiès's work (2014) was proposed, where the following aspects of the mediation process were analyzed, such as the documentary process, the informational process and the communicational process. The library was chosen according to accessibility sampling criteria, having a librarian in its staff that develops reading actions with student groups. The research was conducted with a group of thirty-six students from the 4th grade of elementary school. Mediation is considered a primary factor for encouraging and building the reading habit, which should be the responsibility not only of the school, but also of the family. 
Keywords: School library; Librarian; Reader; Reading; Mediation.

Recebido em 15.10.2018 Aceito em 13.05.2020

\section{Introdução}

Sendo a biblioteca escolar um espaço para a construção e a ampliação da cultura e do conhecimento, cabe à escola fazer bom uso dos recursos informacionais e tecnológicos para atrair a atenção e o interesse de seus alunos pelo hábito da leitura, e, assim, usufruir de fontes de informação que complementem os conteúdos abordados em sala de aula. A biblioteca escolar visa adisseminação da informação e o uso frequente deste espaço é fundamental para o pleno desenvolvimento do processo de ensino-aprendizagem.

A biblioteca não tem seu espaço dentro do ambiente escolar reconhecido como espaço do saber, sendo reconhecida por vezes até como espaço de punição e para onde são enviados funcionários que estão com problemas de saúde ou que estão próximos da aposentadoria.

A biblioteca escolar precisa ser reconhecida pelo professor e por toda a comunidade escolar como uma unidade rica em informação e conhecimento e não como uma sala de castigo ou depósito de livros. Desta forma, pode-se dizer que a biblioteca escolar existe para atender às necessidades informacionais dos alunos, professores, coordenadores, enfim de toda a comunidade escolar.

Os profissionais da informação nem sempre estão presentes nas bibliotecas escolares, porém, são eles que devem desenvolver atividades de incentivo e mediação da leitura juntamente com os professores. Neste contexto, bibliotecário e professor tonam-se personagens principais no processo de ensino-aprendizagem, para isto, faz-se necessário pensar em propostas pedagógicas que integrem a biblioteca escolar ao projeto pedagógico da escola.

A questão central que norteou esse estudo foi: como a mediação da leitura pode contribuir para a formação de leitores na biblioteca escolar? Pelo exposto, este trabalho tem como objetivo geral discutir a biblioteca escolar como espaço privilegiado para amediação de leitura a partir da percepção dos alunos. Os objetivos específicos são: analisar as práticas de mediação na biblioteca escolar como potencializadoras da leitura; identificar a biblioteca escolar como espaço privilegiado para mediação da leitura; e discutir o papel do bibliotecário na promoção da aprendizagem e da leitura.

A aprendizagem de habilidades informacionais nas escolas deve contar com o apoio do profissional da informação, pois cabe ao bibliotecário a tarefa de disponibilizar os recursos informacionais aos 
usuários da biblioteca escolar, assim como capacitá-los na utilização de diferentes suportes e fontes de informação.

Pelo exposto, reforça-se a importância dessa pesquisa pela possibilidade de discutir a mediação da leitura e a atuação dos profissionais da informação e educadores na condução de processos que visam elevar o acesso à biblioteca escolar, e, consequentemente, o acesso à leitura, despertando o prazer que é ler e se encantar com o mundo dos livros.

\section{Biblioteca escolar}

A biblioteca escolar é essencial para a formação de leitores que, através da leitura, podem desenvolver o pensamento crítico e reflexivo e a construção do conhecimento, estabelecendo a possibilidade de melhor comunicação para uma vida em sociedade.

O Manifesto da IFLA/UNESCO para a biblioteca escolar no ensinoaprendizagem para todos, que foi publicado em 2000, fala sobre a missão e os objetivos da biblioteca escolar e que ela deve proporcionar informações e ideias, habilitando os estudantes para desenvolver a imaginação, preparando-os para a aprendizagem ao longo da vida, tornando-se cidadãos responsáveis, promovendo serviços de apoio aos membros da comunidade escolar, capacitando-os para se tornarem leitores críticos e reflexivos, habilitados a usar a informação em qualquer meio e suporte (IFLA/UNESCO, 1999).

O papel do bibliotecário escolar é de grande importância para atingir tais objetivos e seu trabalho deve ser desenvolvido em conjunto com todos os membros da comunidade escolar. Seu perfil deve ser inovador e determinante para acompanhar o avanço das tecnologias da informação e da comunicação (TIC), com habilidades para o manuseio da informação em diferentes formas de suporte, buscando contínuo aperfeiçoamento profissional e competência para lidar com a informação. A parceria entre professores e bibliotecários influencia no bom desempenho dos alunos no processo de ensino-aprendizagem no espaço da biblioteca.

Dentre as ações públicas visando o desenvolvimento da leitura foi criado, em 1997, o Programa Nacional Biblioteca da Escola (PNBE) pelo Ministério da Educação e da Cultura (MEC) em parceria com a Secretaria de Educação do Distrito Federal (SEDF), com a intenção de promover nas Escolas Públicas de Ensino Fundamental recursos diversificados de leitura, essenciais ao desenvolvimento intelectual, emocional e cultural de alunos e professores (COPES; SAVELI, 2007).

Em 2014, o PNBE foi destinado a prover as escolas de ensino público das redes federal, estadual, municipal e do Distrito Federal, no âmbito da educação infantil (creches e pré-escolas), do ensino fundamental, do ensino médio e educação de jovens e adultos (EJA), com o fornecimento 
de obras e demais materiais de apoio à prática da educação básica. 0 principal objetivo era democratizar e disponibilizar o acesso de livros aos alunos de outras séries e da comunidade ao acervo (CIRINO, 2015).

Porém, a criação do programa de ações de incentivo à leitura não é suficiente para a formação de leitores. A disponibilização de livros para a biblioteca escolar exige um espaço físico adequado, além de planejamento, organização e ações que possam atrair o interesse dos alunos e permitir o acesso ao livro.

O uso das bibliotecas pelos aprendizes deve se iniciar desde a educação infantil, por isso a biblioteca escolar tem papel preponderante no que diz respeito a fomentar nos aprendizes a curiosidade, a vontade de aprender, o gosto pela leitura. Para tanto, as bibliotecas precisam estar integradas pedagogicamente ao sistema educacional, em especial as escolares (GASQUE, 2012, p.153).

É primordial que os alunos aprendam desde cedo a importância da biblioteca dentro do ambiente escolar como fonte de informação e conhecimento, para que se tornem leitores com perfil crítico e reflexivo, adquirindo habilidades e competências para buscar, recuperar e avaliar as informações que necessitam para, assim, aprender constantemente contribuindo para sua vida social e acadêmica. O seu distanciamento ou falta de conhecimento sobre o uso e a importância da biblioteca escolar demostra a realidade de muitas escolas, onde os alunos não recebem o incentivo de seus professores e limitam-se apenas aos conteúdos dos livros didáticos.

A integração do bibliotecário junto ao corpo docente deve ser considerada como uns dos principais fatores que influenciam no processo de ensino-aprendizagem. As pesquisas propostas pelo professor ampliam o conhecimento sobre os conteúdos aprendidos em sala de aula e neste contexto a participação do bibliotecário torna-se fundamental para orientar os alunos a buscar informações usando os suportes disponíveis na biblioteca.

A matéria prima da biblioteca escolar, em qualquer um dos papeis que desempenha, é a informação, a qual está intimamente ligada à geração e construção do conhecimento e é a responsável direta pela formação profissional do aluno. O conhecimento adquirido na biblioteca escolar o acompanhará durante toda vida (CÔRTE; BANDEIRA, 2011, p.6). 
Diante da colocação de Côrte e Bandeira (2011) é possível dizer que uma das principais funções da biblioteca escolar é a disseminação da informação, onde o aluno, ao procurar a biblioteca, busca novas informações para ampliar o seu conhecimento. Os alunos precisam ter consciência da importância da biblioteca escolar em suas vidas, dos vários benefícios que ela pode proporcionar para sua formação intelectual e social, para que possam fazer uso dos recursos informacionais disponibilizados pela biblioteca e aprimorar o seu conhecimento.

A função da biblioteca escolar não se resume ao empréstimo de livros, sua função deve ser educativa, possibilitando aos seus usuários o acesso ao acervo com obras literárias e recursos que atendam suas necessidades informacionais, formando parceria com os membros da escola para a formação de leitores.

O espaço deve ser atrativo e a participação de um profissional bibliotecário torna-se fundamental no tratamento e organização da informação, tornando-a acessível aos usuários, além de contribuir com ações e projetos que despertem nos alunos o desejo de ler. Professores e bibliotecários devem agir em parceria para o desenvolvimento de atividades educativas e ações culturais, tornando a biblioteca um instrumento pedagógico, motivando e incentivando o hábito e o prazer pela leitura, proporcionando vários benefícios aos alunos.

A participação do professor nesse processo torna-se essencial, pois é importante que incentive seus alunos a frequentarem a biblioteca como fonte de informação e complementação aos conteúdos abordados em sala de aula. Desta forma, a biblioteca pode contribuir para que os alunos ampliem seu conhecimento e desenvolvam sua formação intelectual (CÔRTE; BANDEIRA, 2011).

A biblioteca é um importante instrumento para a construção e ampliação do conhecimento, pois o aluno que recebe o incentivo de frequentá-la desde a educação básica passa a reconhecer sua importância para a sua formação social e intelectual e, portanto, ao ingressar na universidade terá maturidade para se tornar um leitor crítico e reflexivo, possuindo a competência de localizar, analisar e recuperar a informação.

Sobre a mediação da leitura na biblioteca, Silva (2015, p. 496), afirma que:

Uma das premissas básicas para mediar à leitura na escola é que o mediador seja leitor, pois desta forma, ele terá mais claro para si mesmo, não apenas as metas pedagógicas, mas a sua própria experiência intima com o texto poderá fazer diferença no processo de mediação. 
As escolas sem bibliotecas limitam-se somente aos livros didáticos e às informações passadas apenas pelo professor em sala de aula. É importante que os alunos se interessem em procurar outras fontes de informação, que reforcem o que foi abordado pelo professor em sala de aula, para que ampliem o seu conhecimento, não tendo como fonte apenas o livro didático.

A habilidade do aluno em localizar a informação permitirá a descoberta de novas fontes e a familiaridade com os recursos informacionais oferecidos pela biblioteca, para a localização e busca da informação. Com isto, a pesquisa escolar torna-se um instrumento poderoso do processo de ensino-aprendizagem (KUHLTHAU, 2013).

O bibliotecário ocupa um papel essencial dentro do ambiente escolar, sua função é fundamental para que a biblioteca não seja apenas um espaço físico dentro da escola e seu papel educativo torna-se essencial para a formação de novos leitores. Além de instruir aos alunos a recuperar e localizar informações, o bibliotecário desempenha uma função social, valorizando a função da biblioteca escolar e atuando na disseminação e mediação da informação, participando do processo de ensinoaprendizagem.

A presença do bibliotecário dentro do ambiente escolar pode trazer vários benefícios à escola e aos seus alunos, entre eles, atividades de incentivo à leitura e formação da competência informacional. O desenvolvimento de projetos educacionais e ações culturais juntos aos professores facilita o aprendizado dos conteúdos abordados em sala de aula.

Além de reconhecer que sua profissão é muito importante e necessária para a sociedade, o bibliotecário deve reconhecer-se como um agente de transformação social. Sua participação no processo de desenvolvimento de competência informacional é indispensável para a formação de leitores críticos e formadores de opiniões.

Para desenvolver o espírito crítico e a postura científica no aluno, seriam necessárias as condições propícias a esse desenvolvimento, como, por exemplo, corpo docente qualificado, boa infraestrutura das escolas e uma proposta curricular ajustada (FIALHO, 2004, p.17).

Para a motivação do gosto e interesse pela leitura é importante propiciar ao leitor alguns aspectos que podem ser considerados essenciais para o incentivo à leitura como: um local adequado, atraente, agradável, dinâmico e interativo que desperte no leitor a vontade de permanecer e se encantar pelo mundo prazeroso da leitura. As escolas devem adequar o espaço físico reservado à biblioteca dentro da escola e transformá-lo em 
espaço da informação e do conhecimento abrindo novos horizontes para seus alunos, professores e toda comunidade escolar (SILVA, 2015).

Neste sentido, o Grupo de Estudos Biblioteca Escolar (GEBE), da Escola de Ciência da Informação da Universidade Federal de Minas Gerais (UFMG), constitui-se um referencial para a qualidade das bibliotecas escolares do país e se dispôs a elaborar parâmetros para a criação e a avaliação de bibliotecas escolares. O processo de elaboração dos parâmetros teve início com um estudo da situação das bibliotecas escolares do país, tendo como base teórica a noção da biblioteca escolar como espaço de aprendizagem (GEBE, 2010).

A biblioteca deve contar com um profissional capacitado responsável, neste caso um bibliotecário e com funcionários para o atendimento aos usuários, preferivelmente em todos os horários em que a biblioteca estiver aberta. Desta forma, a composição dessa equipe na biblioteca deve ser definida da seguinte maneira: para o nível básico a biblioteca deve contar com um bibliotecário supervisor que seja responsável por um grupo de bibliotecas, no nível exemplar deve contar com um bibliotecário responsável pela biblioteca e pessoal auxiliar em cada turno, levando em consideração o número de alunos da escola (GEBE, 2010).

Percebe-se que em algumas bibliotecas escolares brasileiras não existe um profissional com formação em Biblioteconomia, em alguns casos esses espaços são ocupados por professores em final de carreira ou que passam por algum problema físico ou psicológico, não tendo nenhuma capacitação para coordenar, planejar, organizar e administrar uma biblioteca (COSTA, 2013).

No Brasil, a Lei 12244/10 de 24 de maio de 2010 (BRASIL, 2010) foi criada para que os municípios e os estados começassem a implantar meios a fim de melhorar a realidade escolar. Apesar dessa lei obrigar todas as instituições de ensino público a terem uma biblioteca até o ano de 2020, dados do Censo Escolar (2016) realizado pelo Ministério da Educação (BRASIL, 2016) mostram que essa meta será difícil de alcançar, pois nem todas as escolas públicas do país tiveram instaladas suas bibliotecas. Nesse sentido, o Projeto de Lei n. 9484/2018, discutido e aprovado no âmbito da Comissão Especial de Educação da Câmara dos Deputados, ampliou para 2024 o prazo para que estados e municípios possam se adequar à Lei 2.244/10, além de trazer como mudanças o art. 20 que trata do conceito de biblioteca escolar, que passa a ser entendida como:

Art. $2^{\circ}$ Para os fins desta Lei, considera-se biblioteca escolar o equipamento cultural obrigatório e necessário ao desenvolvimento do processo educativo, cujos objetivos são: I - disponibilizar e democratizar a informação, ao conhecimento e às novas 
tecnologias, em seus diversos suportes; II - promover as habilidades, competências e atitudes que contribuam para a garantia dos direitos e objetivos de aprendizagem e desenvolvimento do(a)s aluno(a)s, em especial no campo da leitura e da escrita; III - constituir-se como espaço de recursos educativos indissociavelmente integrado ao processo de ensino-aprendizagem; IV - apresentar-se como espaço de estudo, encontro e lazer, destinado a servir de suporte para a comunidade em suas necessidades e anseios.

Essa e outras alterações ampliam a abrangência da lei e a noção de biblioteca escolar, possibilitando a esse equipamento cultural atuar como articulador de ações conjuntas de ensino-aprendizagem nas escolas e contribuir diretamente na formação dos alunos e para a democratização do acesso à informação e ao conhecimento, não apenas para a comunidade escolar, mas para a comunidade como um todo.

Algumas escolas possuem o espaço físico para a utilização da biblioteca, porém esses espaços não são utilizados como deveriam. A presença de um profissional qualificado torna-se primordial para o bom funcionamento da biblioteca, cabendo a este profissional a missão não só de organizar e preparar a informação para o usuário, mas de atraí-los cada vez mais, transformando-os em novos leitores através da mediação da informação e da leitura.

\subsection{Leitura e aprendizagem}

Sabe-se que a leitura é de suma importância para a formação intelectual, social e cultural do indivíduo. O contato com os livros nos primeiros anos de vida desperta o interesse pelo gosto e hábito da leitura, além de oferecer vários benefícios à formação de cada cidadão. Saber ler é primordial para uma vida em sociedade e o incentivo é muito importante para se adquirir o hábito da leitura.

A leitura não se resume apenas à leitura obrigatória, aquela que é feita por indicação ou exigência do professor, mas deve ser vista também como uma atividade prazerosa que desperte a atenção e o prazer do leitor. O incentivo à leitura não é uma obrigação apenas da escola, pois essa iniciativa deve partir também dos bibliotecários e também dos pais.

Segundo Silva (2009), é possível distinguir três formas de leitura: leitura mecânica, leitura do mundo e leitura crítica. Define-se a leitura mecânica como a habilidade de decifrar códigos e sinais, já a leitura do mundo é um processo continuado, que começa no berço e só se encerra no leito da morte, e por fim, a leitura crítica que alia a leitura mecânica à leitura do mundo e, de forma avaliativa, compara a leitura do momento com outras já feitas, tendo a capacidade de estimular ao leitor questionar 
e tirar conclusões. A leitura oferece vários benefícios ao leitor, tais como: melhor expressividade, a ampliação do vocabulário, a aquisição de novos saberes e a construção do conhecimento.

O processo de alfabetização e letramento deve-se iniciar na educação infantil, fase em que a criança conhece o mundo da decodificação das primeiras palavras e da escrita. A alfabetização referese ao processo de aprendizagem da leitura e da escrita. Já o letramento relaciona-se às práticas e habilidades de uso da leitura e da escrita, levando o indivíduo a adquirir benefícios e a envolver-se no meio social e cultural (SOARES, 1999).

Os profissionais atuantes na biblioteca devem ser capacitados para atender e saber identificar cada necessidade do usuário, abordá-lo e ajudá-lo em caso de dúvidas e indecisões. O usuário deve sentir confiança ao pedir ajuda e ter a certeza que terá suas expectativas atendidas. A biblioteca deve ter seu acervo diversificado de acordo com as necessidades dos usuários, mantendo-o sempre atualizado.

Os alunos precisam sentir-se atraídos pela biblioteca, com desejo de permanecer e voltar ao local, que deve ser atrativo e propício para o desenvolvimento de atividades que despertem o interesse do aluno pela leitura.

O que se percebe é que algumas escolas possuem bibliotecas, mas geralmente não são utilizadas de forma adequada por vários fatores: ausência de profissionais capacitados, as condições do acervo são precárias e o acesso é restrito em alguns casos, só sendo possível com o acompanhamento do professor. Desta forma, o incentivo à leitura é uma atividade inexistente nestas escolas e os alunos, consequentemente, não conhecerão a prática da leitura e se tornarão reféns apenas dos livros didáticos, das informações passadas pelo professor e da leitura mecânica.

É preciso que os alunos tenham consciência da função e importância da biblioteca escolar para sua formação intelectual e social e conheçam os benefícios proporcionados através da leitura para que se tornem leitores letrados, não apenas alfabetizados.

\subsection{Mediação e mediação da leitura}

A mediação encontra-se presente em diversos contextos da sociedade. O processo de mediação ocorre com a participação de um mediador e, no presente trabalho, considera-se como principal mediador o bibliotecário, que deve atuar em parceria com os professores e familiares para o desenvolvimento do hábito e o prazer da leitura nas bibliotecas escolares.

Sobre o mediador da informação, Almeida Júnior e Bortolin (2007, p. 8) afirmam que: 
[...] Medianeiro, mediatário ou mediador é todo profissional que tem a responsabilidade de acompanhar um leitor durante a sua formação ou mesmo depois de formado (na medida em que a formação é continua) quando em dúvida ou desencorajado, solicita uma sugestão.

Para incentivar o gosto e o prazer pela leitura é essencial que primeiramente o mediador goste de ler e demonstre domínio sobre a leitura. Sua função é considerada muito importante para a formação de novos leitores. Para isto o mediador, ou o agente de leitura, deve ter o compromisso de preparar-se para atrair diferentes públicos e levar a mediação da leitura a diversos ambientes e comunidades.

Entende-se que a mediação da informação serve como estímulo e exerce uma função primordial na promoção do diálogo, para indicar possíveis caminhos para o desenvolvimento de competências e, consequentemente para subsidiar o protagonismo social (FARIAS, 2016, p. 108).

A mediação da leitura deve ocorrer de forma abrangente, onde possa atrair jovens, adultos e crianças. A mediação da leitura pode ser vista como uma atividade social, onde o principal objetivo é transformar em leitores aquelas pessoas que desconhecem a leitura como uma prática que desenvolve o senso crítico, criativo, social e cultural e que não acreditam que a leitura possa transformar suas vidas e abrir novos horizontes.

O professor também é considerado um mediador da leitura e deve reconhecer essa atividade como uma prática pedagógica, entendendo a importância de formar leitores dentro do ambiente escolar para que se tornem cidadãos alfabetizados e letrados adquirindo competências informacionais para localizar e organizar a informação.

De acordo com Almeida Júnior e Santos Neto (2014, p. 99), "a organização do conhecimento e da informação sempre acompanhou as pessoas e as organizações. Nas unidades de informação e nas empresas, a preocupação é com o acesso as informações". O acesso à informação torna-se possível através do tratamento dado pelos profissionais capacitados de cuidar, organizar e recuperar a informação para satisfazer as necessidades dos usuários. Sobre a mediação, os autores afirmam:

A mediação só ocorre quando há interferência de alguém, este que interfere é denominado como mediador. É simples entendermos como um mediador pode facilitar muitas conversas e acordos, mesmo que sem desconsiderá-la ou manipulá-la. Da mesma forma que o termo mediação é utilizado e empregado em diversas áreas 
do conhecimento, o mediador também está presente nelas (ALMEIDA JÚNIOR; SANTOS NETO, 2014, p.100).

O bibliotecário não deve preocupar-se apenas em organizar a informação, mas em disseminá-la. Para exercer o seu papel como profissional da informação, sua atividade deve estar interligada com o processo de mediação.

A mediação da informação pode ser vista como prática pedagógica e social, contribuindo para a construção do conhecimento. Na biblioteca escolar o bibliotecário torna-se o personagem principal para o processo de mediação da informação e sua participação é fundamental tanto na mediação implícita como na explícita.

Segundo Nunes (2015, p.15), "a mediação é um elemento fundamental no processo que pode levar alguém a aprender, a adquirir conhecimentos e a interagir de modo mais consciente em sua comunidade e na sociedade em que habita".

Para desenvolver seu papel na educação, os profissionais da informação precisam capacitar-se para desenvolver competências, habilidades técnicas, cognitivas intelectuais e culturais. Estes requisitos permitirão trabalhar e operar na disseminação da informação reconhecendo no seu objeto de trabalho a informação e sua função social. A atuação do bibliotecário na disseminação da informação é fundamental, pois além de organizar a informação exerce o papel de mediador contribuindo para formação de outros profissionais (NUNES, 2015).

A mediação se insere no contexto pedagógico sendo representada por dispositivos, ações e conjuntos de ações que apoiam as relações entre atores e o ensino, da formação e da pesquisa, sendo inserida também na noção processual, expressando fenômenos observados na ação de mediar. Segundo Gardiès ${ }^{1} a$ mediação numa perspectiva pedagógica pode ser desenvolvida através de dispositivos que facilitam a apropriação da informação e que foram observados pela autora numa sessão de classe invertida, com um grupo de cinco professores.Classe invertida pode ser considerada, segundo Gardiès (2014, tradução nossa), um ambiente ou

\footnotetext{
${ }^{1}$ CécileGardiès é professora do ensino superior em ciências da informação e comunicação na ÉcoleNationaleSupérieure de Formation de I'EnseignementAgricole de Toulouse-Auzeville (ENFA), na França. Sua pesquisa questiona os desafios do compartilhamento do conhecimento em uma abordagem teórica e epistemológica em torno dos conceitos de informação-conhecimento, mediação e dispositivos. Dois eixos são explorados, o primeiro diz respeito à didática da informação por meio de práticas de ensino-aprendizagem em sala de aula ou fora dela. O segundo diz respeito à mediação digital do conhecimento em suas dimensões linguística, simbólica e técnica. Do ponto de vista metodológico, no campo do ensino médio, desenvolve uma abordagem colaborativa e qualitativa, principalmente em torno da captura de vídeos e entrevistas com os participantes de suas pesquisas. (Tradução nossa). Disponível em: https://cv.archivesouvertes.fr/cgardies Acesso em: 01 nov. 2019.
} 
espaço onde ocorre a hibridação de práticas, e que "[...] parte da ideia de utilizar de uma outra maneira o tempo de classe notadamente para interagir e trabalhar o conjunto, muito mais que deixar o professor transmitir conhecimentos".

Sua experiência visou observar neste dispositivo pedagógico o processo de mediação e apropriação da informação através da forma de disposição organizada pelos professores das informações a serem aprendidas e apropriadas pelos alunos. Desta forma, foram identificados por Gardiès três tipos de processos relacionados à ação mediadora, são eles: processo informacional, processo documentário e processo comunicacional (GARDIÈS, 2014, grifo nosso).

O processo informacional relaciona-se à transformação da informação em conhecimento, adquirido através de diferentes suportes e recursos informacionais. Já o processo documentário caracteriza-se pela forma como a informação é levada a diferentes públicos em diferentes suportes, levando em consideração o tratamento que o profissional desenvolve para disponibilizar a seu público a informação de forma eficiente e eficaz contribuindo para a construção do conhecimento (GARDIÈS, 2014).

$\mathrm{E}$, por fim, o processo comunicacional que acontece no momento em que mediador e mediado utilizam-se de argumentações ou questionamentos orais para expressarem suas ideias dando sentido à informação obtida através da mediação da leitura ou da informação. Ao finalfoi possível observar indícios de como os alunos se apropriaram da informação a partir do dispositivo proposto e das práticas desenvolvidas nos processos informacional, documentário e comunicacional, posto que a reescrita, a reformulação de conhecimentos e a construção de sentidos denotam a importância da mediação que promove a relação entre os professores, os profissionais e os aprendizes visando a aprendizagem e a formação de saberes (GARDIÈS, 2014).

A mediação exige que o profissional da informação saiba atuar de forma direta ou indireta na disseminação da informação e na mediação da leitura, atribuindo-se recursos e meios de modo planejado, organizado e intencionado possuindo habilidades e competências para agir como mediador.

Os docentes precisam refletir sobre como desenvolver sua função como educadores e mediadores assumindo seu papel de transformador, despertando nos alunos o senso crítico e reflexivo para modificar-se culturalmente. Para desenvolver seu papel como mediador da leitura e da informação, o mediador essencialmente deve gostar de ler. Desse modo, seus alunos entenderão que a prática da leitura é uma atividade prazerosa que pode trazer vários benefícios à sua vida. A mediação é o principal 
elemento para apresentar o livro ao aluno, levando em consideração seu nível cultural e sua realidade.

É fundamental que o aluno, o professor e o bibliotecário compreendam que a concretização efetiva da pesquisa escolar ocorre por etapas e não em bloco único, e que a riqueza do processo se traduz na modificação da forma de pensar do estudante (CAMPELLO et al., 2008, p. 27).

O desenvolvimento da pesquisa escolar não se resume à cópia de trechos de texto da internet ou simplesmente ao material dado pelo bibliotecário ou professor para a realização da pesquisa. Professor e bibliotecário devem orientar seus alunos no desenvolvimento da pesquisa e nunca conceder a página exata onde consta a informação, pois, desta forma, não estarão contribuindo para a evolução do processo de ensinoaprendizagem possibilitando a oportunidade de adquirir habilidades para realizar essa tarefa.

Percebe-se na realidade brasileira a presença de elementos importantes para o desenvolvimento da cultura informacional nas escolas da educação básica, mas que ainda necessitam de maior sistematização e integração. (FIALHO, 2009, p.168).

O aluno deve reconhecer a importância da biblioteca, para a realização de suas pesquisas como fonte de informação para aprimorar-se no tema escolhido, neste sentido a participação do bibliotecário escolar no processo de orientação e, disponibilização do acesso á informação é fundamental.

A familiaridade com a biblioteca escolar aumenta a possibilidade do aluno em exercer habilidades de pesquisa e a capacidade de usar os recursos informacionais disponibilizados pela biblioteca para localizar, recuperar e organizar a informação, sendo capaz de interpretar quais informações serão úteis para sua pesquisa, dominando técnicas para resumir e parafrasear (CAMPELLO et al., 2008).

Os mediadores assumem uma importante participação nesse processo da pesquisa escolar, e professor e bibliotecário devem instruir aos alunos como realizar suas pesquisas indicando fontes e orientando-os sobre como proceder. Percebe-se que os professores não esclarecem como desejam a pesquisa, causando confusão e falta de estímulo ao aluno.

A pesquisa escolar é um relevante instrumento para o processo de ensino-aprendizagem, porém, para que contribua de forma significante para o desenvolvimento intelectual do aluno, deve ser realizadade maneira correta. O fato apenas do professor utilizar a pesquisa como 
recurso pedagógico sem uma orientação, não desperta no aluno o senso crítico e a curiosidade de procurar novas fontes de informação para a realização de suas pesquisas. Bibliotecários e professores devem exercer suas funções como educadores e mediadores para estabelecer a aproximação do aluno na biblioteca escolar e capacitá-los para o uso dos recursos informacionais.

A biblioteca é uma agência mediadora e o bibliotecário age como mediador da leitura e essa tarefa é tão importante quanto o ato de organizar a informação e disponibilizá-la. Trabalhar na mediação da leitura não é uma tarefa fácil, por isso essa iniciativa deve começar no ambiente familiar, dando-se continuidade nas escolas, bibliotecas, empresas, igrejas e movimento sociais. A sobrecarga do trabalho leva o leitor a fazer uma leitura superficial do texto não despertando seu senso crítico (BORTOLIN, 2010).

O que se percebe é que a mediação da leitura não é vista como umas das principais atividades das bibliotecas sejam elas, públicas, universitárias ou escolares. Algumas bibliotecas interessam-se apenas em disponibilizar a informação, organizando e preparando seu suporte, porém, isso não é suficiente para a formação de leitores. A mediação da leitura exerce um papel fundamental na formação da cidadania e garante através de suas práticas a contribuição para a aquisição do conhecimento e o desenvolvimento intelectual, formando cidadãos competentes para ler diferentes textos.

\section{Metodologia}

A metodologia utilizada para a realização do trabalho funda-se na noção de que a mediação da leitura é uma ação que contribui para a apropriação e o uso da informação, podendo levar o indivíduo a modificar sua condição social. Parte, então, do paradigma social da Ciência da Informação, segundo o qual a informação é inserida num processo que envolve produção, coleta, organização, interpretação, armazenamento, recuperação, disseminação, transformação e uso dentro das relações estabelecidas entre os grupos sociais (CAPURRO, 2003).

Para atingir os objetivos, foi desenvolvida a pesquisa de nível exploratório e de abordagem qualitativa. A pesquisa exploratória tem como objetivo apropriar um olhar generalizado e aproximado sobre um determinado fato, ocorrendo principalmente quando o tema é considerado pouco explorado e dificilmente é possível formular hipóteses (GIL, 2008).

A proposta metodológica empírica baseou-se na observação participante e na análise da aprendizagem a partir de experiências de leitura dentro do espaço da biblioteca. Sobre a observação participante Marconi e Lakatos (2003, p.192) afirmam: 
Consiste na participação real do pesquisador com a comunidade ou grupo. Ele se incorpora ao grupo, confunde-se com ele. Fica tão próximo quanto um membro do grupo que está estudando e participa das atividades normais deste.

Foi escolhida a Biblioteca do SESC Siqueira Campos, na cidade de Aracaju, Sergipe por critério de amostragem por acessibilidade, possuindo as seguintes características: possui bibliotecário (s) em seu quadro de funcionários que desenvolve ações de leitura com turmas de alunos e essas ações têm integração com as disciplinas da escola.

Segundo Gil (2008, p. 94), a amostragem por acessibilidade ou por conveniência pode ser definida da seguinte forma:

Constitui o menos rigoroso de todos os tipos de amostragem. Por isso mesmo é destituída de qualquer rigor estatístico. O pesquisador seleciona os elementos a que tem acesso, admitindo que estes possam de alguma forma, representar o universo. Aplica-se este tipo de amostragem em estudos exploratórios ou qualitativos, onde não é requerido elevado nível de precisão.

Este desenho metodológico parte de uma adaptação do trabalho de Gardiès (2014), onde são analisados os seguintes aspectos no âmbito do processo de mediação: o processo documentário, o processo informacional e o processo comunicacional.

Definida a instituição e a biblioteca, a etapa seguinte baseou-se no acompanhamento de uma ação de mediação de leitura. Foi proposta uma atividade de mediação que explorasse a aprendizagem sobre a história do Carnaval através dos três processos de mediação.

Desta maneira, a bibliotecária selecionou a turma do 40 ano do ensino fundamental para participar da atividade, possuindo 36 alunos, sendo crianças entre 9 e 10 anos. Porém, dos 36 participantes, um possuía necessidades especiais, e ficou agitado durante a atividade, sendo levado para a área de recreação da escola, não participando da atividade, resultando em 35 alunos participantes.

Segundo a bibliotecária, a turma do 40 ano do ensino fundamental foi escolhida para participar da atividade de mediação da leitura devido à sua interação com a professora, que desenvolve diversas atividades com alunos no espaço da biblioteca, participando também das ações promovidas pela biblioteca.

A ação de mediação foi realizada no espaço da Biblioteca do SESC Siqueira Campos com o tema"História do Carnaval", tendo a parceria da professora e da bibliotecária.

A partir dessa ação, os participantes foram convidados a escrever sobre o que perceberam a partir da leitura e qual a aprendizagem obtida. 
Os dados foram apresentados a partir da própria percepção dos alunos e transpostos para a discussão dos resultados a fim de se chegar às conclusões do trabalho, baseadas nos objetivos inicialmente traçados.

Após a aplicação da atividade do processo mediador com os alunos foi feita uma entrevista com a bibliotecária da Biblioteca do SESC Siqueira Campos a fim de avaliar sua percepção sobre os resultados da atividade de mediação da leitura no espaço da biblioteca. A entrevista foi feita face a face, utilizando um gravador de áudio, com autorização da entrevistada e transcrita para os resultados.

\section{Resultados}

A análise dos dados será apresentada com base nos três processos de mediação propostos por Gardiès (2014).

\subsection{O processo documentário}

No primeiro momento ocorreu a ação de mediação da leitura com a turmado $4^{\circ}$ ano do ensino fundamental, com o tema História do Carnaval. Todos os anos os alunos da Escola SESC Siqueira Campos comemoram o Carnaval, no entanto não sabiam qual a origem da festa e como surgiu no Brasil, e com a realização da atividade todos tiveram a oportunidade de conhecer a história do Carnaval, a festa mais comemorada no Brasil.

O texto foi elaborado através de pesquisas, sua elaboração foi desenvolvida de acordo com a faixa etária dos alunos, uma turma do 40 ano do ensino fundamental, com crianças de 9 a 10 anos. Conforme a bibliotecária, o texto não poderia ser muito longo e o vocabulário teria que abranger o entendimento das crianças.

Depois de todos estarem acomodados e em silêncio, deu-se início à leitura do texto. Cada aluno recebeu uma cópia para acompanhamento da leitura. Observou-se nesse momento que os alunos ficaram bem atentos. Após a leitura e a explicação do texto, foi exibido um vídeo com imagens que mostraram como o Carnaval era comemorado no passado e como é comemorado nos dias atuais, foi possível observar que as imagens chamaram a atenção dos alunos.

Com base na observação da ação e a análise dos dados é possível dizer que no primeiro momento foi desenvolvido o processo documentário, onde houve o tratamento da informação e a preocupação de como a informação chegaria aos alunos visando facilitar o entendimento e o acesso à informação.

O processo documentário define-se pela maneira como o profissional trata e desenvolve a informação para levá-la a diferentes públicos em diferentes suportes, disponibilizando-a (GARDIÈs, 2014).

Constatou-se que a mediação da leitura chamou a atenção dos alunos, pois a forma de como a mediação ocorreu ajudou bastante no 
entendimento sobre o tema abordado, levando a compreender que a aprendizagem através da mediação da leitura está relacionada à maneira de como o mediador interage e se expressa. Outro ponto analisado foi o planejamento para a realização da atividade, onde o texto foi elaborado e preparado pensando na faixa etária das crianças, de forma que pudesse atrair a atenção, o entendimento e facilitasse a aprendizagem.

Analisou-se, nesse primeiro momento, que a ação de mediação da leitura realizada no espaço da biblioteca escolar desperta a atenção dos alunos, desenvolve a aprendizagem de forma prazerosa, saindo da rotina da sala de aula e estimulando o uso da biblioteca, reforçando a percepção de Côrte e Bandeira (2011) quanto à participação do professor em conjunto com a biblioteca escolar.

A participação do professor nesse processo torna-se essencial, pois é importante que incentive seus alunos a frequentarem a biblioteca como fonte de informação e complementação aos conteúdos abordados em sala de aula. Desta forma, a biblioteca pode contribuir para que os alunos ampliem seu conhecimento e desenvolvam sua formação intelectual (CÔRTE; BANDEIRA, 2011).

\subsection{0 processo informacional}

No segundo momento da ação os alunos foram convidados a descrever o que haviam entendido através da mediação da leitura.

Após a leitura, a explicação do texto e a apresentação do vídeo, a bibliotecária e a professora distribuíram folhas de papel A4 para cada aluno, orientando-os a descrever o que haviam entendido sobre a leitura. Nesse momento, alguns alunos perguntaram se poderiam desenhar algo que representasse o carnaval. A bibliotecária respondeu que eles tinham que descrever o que haviam entendido e ao final podiam fazer um desenho.

Os alunos se dividiram em grupos de 4 a 5 alunos em cada mesa na sala de leitura, alguns se acomodaram na gibiteca onde se localiza também o acervo infantil, já que no espaço da sala de leitura não foi possível acomodar todos os alunos.

Nesse segundo momento da atividade foi possível observar a dificuldade que os alunos tiveram em descrever o que haviam entendido, pois não tinham experiências em elaborar um texto com suas próprias palavras.

Para Alliende e Condemarín (2005) a familiarização dos alunos com os textos impressos desenvolve habilidades de escrita e amplia o vocabulário. A leitura estimula e desperta o intelecto e a produção de texto, quem lê está disposto a novos desafios e a mudanças em sua vida cultural e social. 
Foi observado, também, que alguns alunos preocuparam-se em perguntar à bibliotecária e a auxiliar da biblioteca se a atividade iria valer ponto, não mostrando interesse na realização.

Analisou-se, nesse segundo momento, que os alunos não gostaram da ideia de fazer uma redação, somente se houvesse "premiação" através de notas. A professora, a bibliotecária e a assistente da biblioteca auxiliaram as crianças durante esse processo, percorrendo todo o espaço da sala de leitura e da gibiteca, orientando-os de como deveriam proceder, informando que não se preocupassem com as letras tortas ou feias o importante era que escrevessem o que haviam entendido.

Após o término da redação, foi solicitado que todos que estavam acomodados no espaço da gibiteca voltassem para sala de leitura e se juntassem aos demais colegas.

Ao final do segundo momento, observou-se que foram poucos os alunos que conseguiram desenvolver a redação. Percebeu-se, então, que mesmo entendendo o texto lido, os alunos sentiram dificuldade para descrever o que haviam entendido, alguns por dificuldade em descrever com suas próprias palavras, outros por falta de interesse ou "preguiça".

Dos 35 participantes iniciais, 16 alunos não entregaram a redação por não terem conseguido desenvolver, um dos alunos apenas desenhou, um escreveu apenas uma palavra, resultando em 17redações para a análise dos dados no segundo momento da ação. A seguir apresentam-se trechos de algumas redações desenvolvidas pelas crianças a partir da aprendizagem obtida por meio da mediação da leitura:

"No carnaval as pessoas se vestem e também se pintam e eu aprendi que o carnaval começou na Europa."

"O carnaval é uma festa comemorada em fevereiro. O carnaval chegou ao Brasil em meados de século XVII."

"A primeira escola de samba foi criada no dia 12 de agosto de 1928, no Rio de Janeiro."

"O carnaval é animado festa popular mais celebrada e mais animada do Brasil o que ao longo do tempo. O carnaval chegou ao Brasil em meado do século. Festas carnavalescas que aconteciam na Europa."

Pode-se dizer que o processo informacional ocorreu neste segundo momento, onde os alunos tiveram a oportunidade de obter 0 conhecimento através da mediação da leitura e descrever a aprendizagem obtida.

O processo informacional refere-se à obtenção da informação através de diferentes suportes, quando há aquisição de conhecimento (GARDIÈs, 2014). 
A dificuldade que os alunos encontraram em desenvolver o texto pode estar relacionada ao fato de ser uma turma do $4^{\circ}$ ano do ensino fundamental, crianças entre 9 e 10 anos, não possuindo desenvoltura suficiente para elaborar um texto com suas próprias palavras. Assim, pode-se considerar que esta fase foi proveitosa e gratificante, pois, se esse tipo de ação for realizado com maior frequência seja na biblioteca ou na sala de aula, os alunos obterão mais desenvoltura e interesse para realização das tarefas diárias, independente da disciplina e dos conteúdos abordados.

\subsection{0 processo comunicacional}

No terceiro momento foi dado início a um debate, onde os alunos foram convidados a expressar oralmente o que haviam entendido sobre o texto. Neste momento, todos os alunos começaram a responder ao mesmo tempo, o que dificultou o entendimento das respostas. Foi pedido para que falassem um de cada vez.

"Eu entendi que o carnaval começou na Europa."

"Eu entendi que as pessoas jogavam água, ovos e farinha nas outras."

"Entendi que o carnaval é uma festa muito comemorada no Brasil."

"Eu entendi que o carnaval começou na França."

"Eu entendi que o povo enfeitava os carros."

"Eu entendi que o carnaval é a festa mais celebrada no Brasil."

Como a atividade só teve a duração de 30 minutos, não foi possível que todos falassem. Nesse terceiro momento, foi possível observar que as crianças tiveram mais facilidade em expressar o que haviam apreendido através da mediação da leitura. Alguns ficaram tímidos e falaram baixinho, outros, porém se sentiram bem à vontade para expor suas ideias.

Pode-se afirmar que a ação de mediação da leitura empreendida ocorreu de forma satisfatória, pois os alunos mostraram-se satisfeitos com a realização da atividade e obtiveram aprendizagem através da mediação.

É possível identificar o terceiro momento como processo comunicacional, onde o receptor atribuiu sentido à informação obtida utilizando-se de questionamentos orais para expor suas ideias obtidas através da mediação da leitura, aprendendo a transformá-la em conhecimento (GARDIÈs, 2014).

Após a aplicação das três etapas do processo mediador, foi realizada uma entrevista com a bibliotecária da Biblioteca do SESC Siqueira Campos a fim de avaliar sua percepção sobre os resultados da atividade de 
mediação da leitura no espaço da biblioteca. Foram feitas as seguintes perguntas:

Como você percebe a importância da biblioteca na contribuição do processo de ensino-aprendizagem?

"A biblioteca é uma parceira da escola, isso já foi comprovado. Todos os serviços que nós realizamos aqui são em prol do aluno, existe a contribuição da Biblioteca SESC para ajudar o aluno no processo de ensino- aprendizagem junto com a escola".

\section{Qual a sua interação com os professores para a realização das atividades desenvolvidas no espaço da biblioteca?}

"Os professores procuram a biblioteca para desenvolver atividades, pois gostam também de participar. Todos os projetos que eu executo tem a parceria da escola com os professores, que também participam. Até mesmo porque, no inicio do ano letivo tem uma reunião pedagógica e todos os anos eu falo com a direção da escola para participar, nas maiorias das vezes tem professor novo (no quadro de funcionários da escola) que ainda não conhece a biblioteca. Então eu preparo uns slides para fazer a divulgação e no dia da reunião pedagógica eu peço uns 10 minutos e faço a divulgação da biblioteca mostrando os serviços e como é composto o acervo. É uma forma de divulgação e também de atrair o professor para a biblioteca".

\section{Como você percebeu os resultados da atividade e a participação dos alunos?}

"Os resultados foram positivos, a maior dificuldade que percebi foi na escrita, quando eu ia passando pela sala de leitura eles ficavam perguntando: tia como se escreve isso... Há uma dificuldade na escrita, aqueles que são mais tímidos não pediram ajuda, ficaram calados e só escreveram uma ou duas palavras. Já aqueles mais espertos perguntavam como escrever e conseguiram fazer duas ou três frases que fizeram a diferença. Na hora de escrever eu percebi certa limitação. Na hora do debate eles ficaram mais a vontade, porque eles percebem que a biblioteca é um espaço acolhedor, que eles já são acostumados a frequentar não é um ambiente novo para eles, então têm mais facilidade para falar. Mais foi muito gratificante porque, mesmo percebendo as dificuldades, que é natural por ser uma turma de $4^{\circ}$ ano, deu para perceber que eles fizeram com prazer".

Os resultados revelam que a mediação da leitura pode contribuir para o processo de ensino-aprendizagem. A prática desta ação no espaço da biblioteca da escola possibilita a aproximação entre escola, alunos, professores e bibliotecário.

Os resultados apontam que a biblioteca escolar pode ser utilizada como um recurso pedagógico e que a interação entre escola e biblioteca, professor e bibliotecário torna-se fundamental para esse processo. 


\section{Considerações finais}

Considera-se que a mediação é um fator primordial para o incentivo e o desenvolvimento do hábito da leitura. Para a formação de bons leitores, as ações e atividades de incentivo à leitura devem se iniciar na educação infantil, porém a responsabilidade não deve ser só da escola, mas também da família.

De acordo com os resultados e a análise realizada, pode-se dizer que a pesquisa atingiu seus objetivos, pois a mediação da leitura desenvolvida no espaço da Biblioteca do SESC Siqueira Campos ocorreu de maneira satisfatória, visto que houve aprendizagem através da ação desenvolvida por meio das três fases do processo mediador, além de ter sido observada a interação entre bibliotecária e professora, ponto fundamental para a promoção de atividades de incentivo à leitura e de estímulo quanto ao uso da biblioteca.

A mediação da leitura possibilita ao mediador interagir com o público, saber sua percepção de entendimento e a aprendizagem a partir da ação realizada. O planejamento, a preparação, a habilidade e a experiência do mediador são pontos fundamentais para alcançar o objetivo desejado.

Considera-se que o profissional da informação que trabalha na biblioteca escolar incrementa um papel educativo, contribuindo para o processo de ensino-aprendizagem. Este profissional deve estar disposto a aceitar novos desafios, preparar-se para desenvolver atividades e projetos de incentivo à leitura que proporcione a seus usuários o desejo de frequentar a biblioteca e fazer uso dos recursos oferecido para complementar as atividades e assuntos abordados em sala de aula.

É na biblioteca escolar que se formam os futuros leitores, a criança que aprende desde a educação infantil a importância da biblioteca escolar para sua vida cultural e social, possuirá competência suficiente para utilizar os serviços, produtos e recursos oferecidos, subsídios fundamentais para uma futura vida acadêmica.

Espera-se que os profissionais da informação avaliem a importância da biblioteca escolar, tanto quanto a universitária, pois é na escola que se iniciam as ações e os projetos para o incentivo e hábito da leitura, que formará leitores críticos e reflexivos que chegaram à vida acadêmica sem dificuldades de utilizar os recursos informacionais e localizar a informação em qualquer meio ou suporte.

A metodologia do presente trabalho, que envolve os três processos de mediação propostos por Gardiès (2014) pode também ser aplicada em outras atividades de pesquisa, quer seja no âmbito de outros tipos de biblioteca, como também envolvendo processos de aprendizagem fora do espaço da biblioteca, como na sala de aula, por exemplo. 


\section{Referências}

ALLIENDE, Felipe; CONDEMARÌN, Mabel. A leitura: teoria, avaliação e desenvolvimento. 8. ed. Trad. Ermani Rosa. Porto Alegre: Artmed, 2005.

ALMEIDA JÚNIOR, Oswaldo Francisco de; BORTOLIN, Sueli. Mediação da informação e da leitura 2007. In: SEMINÁRIO EM CIÊNCIA DA INFORMAÇÃO, 2. 2007, Londrina. Anais [...] Londrina: UEL, 2007. Disponível em:

http://eprints.rclis.org/13269/1/MEDIA\%C3\%87\%C3\%830 DA INFORMA $\%$ C3\%87\%C3\%830 E DA LEITURA.pdf.Acesso em: 8 jul. 2016.

ALMEIDA JÚNIOR, Oswaldo Francisco de; SANTOS NETO, João Arlindo dos. A mediação da informação e a organização do conhecimento:

Interrelações. Informação \& Informação, Londrina, v. 19, n. 2, p. 98-116, maio 2014. Disponível em:

http://www.uel.br/revistas/uel/index.php/informacao/article/view/16716. 12 jul. 2016.

BORTOLIN, Sueli. Mediação oral da literatura: a voz do bibliotecário lendo ou narrando. 2010. 233 f. Tese (Doutorado em Ciência da Informação) Faculdade de Filosofia e Ciências de Marília, Universidade estadual Paulista Júlio de Mesquita Filho, 2010. Disponível em:

https://repositorio.unesp.br/handle/11449/103349. Acesso em: 21 set. 2016.

BRASIL. Senado Federal. Lei $n^{\circ} 12.244$ de 24 de maio de 2010. Dispõe sobre a universalização das bibliotecas nas instituições de ensino do País. Disponível em: http://www.planalto.gov.br/ccivil 03/ ato20072010/2010/lei/l12244.htm\#: : text=LEI\%20N\%C2\%BA\%2012.244\%20D E\%2024,Art. Acesso em: 09 out. 2016.

BRASIL. Congresso Nacional. Projeto de lei $s / n^{\circ}$, de 2018 de autoria da sra. deputada federal Laura Carneiro (em tramitação). Altera a Lei no 12.244 , de 24 de maio de 2010, que dispõe sobre a universalização das bibliotecas escolares nas instituições de ensino do País, para dispor sobre uma nova definição de biblioteca escolar e cria o Sistema Nacional de Bibliotecas Escolares (SNBE). 2018. Disponível em:

https://www.camara.leg.br/proposicoesWeb/prop mostrarintegra;jsession id=499EB29BE91DC709C803F307591EEBE2.proposicoesWebExterno2?cod teor $=1639337 \&$ filename $=P L+9484 / 2018$. Acesso em: 01 nov. 2019.

BRASIL. Instituto Nacional de Estudos e Pesquisas EducacionaisAnísio Teixeira-INEP. Censo Educacional. 2016. Disponível em: http://censobasico.inep.gov.br/censobasico/\#/. Acesso em: 01 nov. 2019. 
CAMPELLO, Bernadete Santoset al. A Biblioteca escolar: temas para uma prática pedagógica. 2. ed. Belo Horizonte: Autêntica, 2008.

CAPURRO, Rafael. Epistemologia e Ciência da Informação. In: ENANCIB ENCONTRO NACIONAL DE PESQUISA EM CIÊNCIA DA INFORMAÇÃO, 5., 2003, Belo Horizonte. Anais [...] Belo Horizonte: UFMG, 2003.

CIRINO, Darciane Barros Leão. Programa Nacional Biblioteca da Escola$P N B E$ : apropriação dos acervos das escolas municipais de Ipameri-GO, 2015. Disponível em: https://files.cercomp.ufg.br/weby/up/549/o/Disserta\%C3\%A7\%C3\%A30 Darciene.pdf. Acesso em: 10 ago. 2016.

CÔRTE, Adelaide Ramos; BANDEIRA, Suelena Pinto. Biblioteca escolar. Brasília, Briquet de Lemos, 2011.

COPES, Regina Janiaki; SAVELI Esméria de Lourdes. Programas, Projetos e Campanhas de Incentivo à Leitura: uma visão histórica. In: CONGRESSO DE LEITURA DO BRASIL, 16., 2007, Campinas. Anais [...] Campinas-São Paulo: UNICAMP, 2007. Disponível em: http://alb.com.br/arquivomorto/edicoes anteriores/anais 16/sem07pdf/sm07ss11 07.pdf. Acesso em: 25 ago. 2016.

COSTA, Jéssica Fernandes. O papel da biblioteca escolar no processo de ensino-aprendizagem. 2013. 94f. Monografia (Bacharelado em Biblioteconomia) - Universidade de Brasília, Brasília, 2013. Disponível em: https://bdm.unb.br/handle/10483/6092. Acesso em: 12 jul. 2016.

FARIAS, Maria Giovanna Guedes. Mediação e competência em informação: proposições para a construção de um perfil de bibliotecário protagonista. InCID: Revista de Ciência da Informação e Documentação, Ribeirão Preto, v. 6, n. 2, p. 106-125, fev. 2016. Disponível em:

http://www.revistas.usp.br/incid/article/view/101368. Acesso em: 30 jan. 2017.

FIALHO, Janaína Ferreira. A formação do pesquisador juvenil. Perspectivas em Ciência da Informação, Belo Horizonte, v. 10 n. 2, p. 194-207, jul./dez. 2004. Disponível em:

http://portaldeperiodicos.eci.ufmg.br/index.php/pci/article/view/343/151A cesso em: 04 ago. 2016.

FIALHO, Janaína Ferreira. Cultura informacional e a formação do jovem pesquisador brasileiro. 2009. 235f. Tese (Doutorado em Ciência da Informação) - Escola de Ciência da informação, Universidade Federal de Minas Gerais, Belo Horizonte, 2009. Disponível em: 
https://repositorio.ufmg.br/handle/1843/ECID-7VYQNZAcesso em: 28 jan. 2017.

GARDIÈS, Cécile. Lectureetappropriation de I'information : enjeux d'undispositifpédagogique de médiationdessavoirs. Ponto de Acesso, Salvador, v. 8, n. 2, p. 124-147, 2014.

GEBE. Grupo de Estudos em Biblioteca Escolar da Universidade Federal de Minas Gerais. Biblioteca escolar como espaço de produção do conhecimento: parâmetros para bibliotecas escolares. Campinas:

Autêntica, 2010. Disponível em:

https://files.cercomp.ufg.br/weby/up/366/o/padroesparabibliotecasescolar es.pdf. Acesso em: 25 set. 2016.

GIL, Antônio Carlos. Métodos e Técnicas de pesquisa social. 6. ed. São Paulo, Atlas, 2008.

IFLA/UNESCO. Manifesto IFLA/UNESCO para a Biblioteca Escolar, 1999. Rio de Janeiro: Fundação Biblioteca Nacional. Disponível em:https://archive.ifla.org/VII/s11/pubs/portuguese-brazil.pdf. Acesso em: 04 ago. 2016

KUHLTHAU, Carol. Como usar a biblioteca na escola: um programa de atividades para o ensino fundamental. 2. ed. Belo Horizonte: Autêntica, 2013.

LEITE, Suellen Moura et al. Lei 12.244/10: uma esperança para as bibliotecas brasileiras. In: CONGRESSO BRASILEIRO DE BIBLIOTECONOMIA, DOCUMENTAÇÃOO E CIÊNCIA DA INFORMAÇÃO, 25., 2013, Florianópolis. Anais [...]São Paulo: FEBAB, 2013. Disponível em: https://portal.febab.org.br/anais/article/view/1253/1254. Acesso em: ago. 2016.

MARCONI, Marina de Andrade; LAKATOS, Eva Maria. Fundamentos da metodologia cientifica. 5. ed. São Paulo: Atlas 2003.

MAROTO, Lucia Helena. Biblioteca escolar eis a questão. Belo horizonte: Autêntica, 2009.

NUNES, Martha Suzana Cabral. Mediação da informação em bibliotecas universitárias brasileiras e francesas. 2015. 219f. Tese (Doutorado em Ciência da informação) - Programa de Pós-graduação em Ciência da Informação, Universidade Federal da Bahia, Salvador, 2015.

SILVA, Rovilson José da. Formar leitores na escola: o projeto pedagógico, a biblioteca escolar e a mediação. Informação \& Informação,Londrina, v.20, n. 3 p.487-506, set./dez.2015. Disponível em: 
http://www.uel.br/revistas/uel/index.php/informacao/article/view/15390/ 17677. Acesso em: 10 jul. 2016.

SILVA, Vera Maria Tietzamann. Leitura literária e outras leituras: impasses e alternativas no trabalho do professor. Belo Horizonte: RHJ, 2009.

SOARES, Magda. Letramento: um tema em três gêneros. 2. ed. Belo Horizonte: Autêntica, 1999. 